\title{
PEMBERDAYAAN MASYARAKAT BARAN, AMBARAWA, SEMARANG, JAWA TENGAH DALAM PROGRAM PERILAKU HIDUP BERSIH DAN SEHAT (PHBS)
}

\author{
Rina Ratih dan mahasiswa KKN Reguler devisi I.A \\ Universitas Ahmad Dahlan Yogyakarta \\ E-mail: ahmad.syihristani@gmail.com
}

\begin{abstract}
Abstrak
Salah satu permasalahan yang ada di masyarakat Kelurahan Baran,Kecamatan Ambarawa, Kabupaten Semarang, Jawa Tengah adalah kurangnya kesadaran masyarakat tentang pentingnya PHBS. Maka program KKN UAD difokuskan pada kebersihan lingkungan. Program ini bertujuan memberdayakan masyarakat Ambarawa dalam program Peduli Lingkungan. Metode pelaksanaan program KKN meliputi: pendidikan masyarakat, difusi teknologi dan praktek langsung. Dampak dari kegiatan KKN ini adalah: 1) tercipta kesadaran masyarakat sasaran tentang pentingnya PHBS, 2) peningkatan pengetahuan masyarakat dalam mengolah sampah, 3) peningkatan pengetahuan masyarakat tentang Demam Berdarah dan bahaya BABs,4) masyarakat terampil membuat karya kreatif dari plastik bekas.
\end{abstract}

Kata Kunci: Bersih, sehat, Baran, KKN

\begin{abstract}
One of the problems that exist in society Baran village, District Ambarawa, Semarang regency, Central Java is the lack of public awareness about the importance of PHBs. Then the UAD learning programs focused on environmental cleanliness. The program aims to empower communities Ambarawa in Environmental Care program. KKN program implementation methods include: public education, the diffusion of technology and practice. The impact of service learning activities are: 1) to create public awareness about the importance of clean and healthy lifestyle goals, 2) increased knowledge of the process waste, 3) increase public knowledge about the dangers of Dengue and Babs, 4) skilled people make creative work of scrap plastic.
\end{abstract}

Keywords: Clean, health, Baran, KKN

\section{A. PENDAHULUAN}

Kelurahan Baran berada di Kecamatan Ambarawa, Kabupaten Semarang, Jawa Tengah. Wilayah kelurahan Baran dapat dijangkau dari Kantor Kecamatan Ambarawa kurang lebih 5 menit dengan jarak kurang lebih 1,5 km.

Kelurahan Baran memiliki topografi dataran tinggi dengan ketinggian tanah $600 \mathrm{~m}$ diatas permukaan laut. Kelurahan Baran memiliki luas wilayah seluas 262.870 ha. Secara garis besar penggunaan lahan di wilayah kelurahan tersebut berupa lahan pertanian yang di dominasi oleh sawah. Lahan terbangun berupa permukiman terdapat di tengah wilayah dan berkembang secara linear mengikuti jaringan jalan.

Akses jalan Kelurahan Baran cukup mudah dilalui oleh kendaraan darat baik roda dua maupun roda empat karena langsung terhubung jalan raya yang menuju Daerah Wisata Bandungan. Keadaan tanah pada Kelurahan Baran adalah subur dan air cukup memadai 
yang berasal dari mata air pegunungan. Masyarakat Kelurahan Baran rata-rata bekerja sebagai petani dan buruh pabrik.

Beberapa permasalahan yang ditemukan di Kelurahan Baran adalah: 1). Banyaknya sampah di lingkungan sekitar yang membuat lingkungan kotor, 2) Kurangnya pengetahuan masyarakat dalam memilah sampah organik dan anorganik, 3) Kurangnya ketrampilan masyarakat dalam memanfaatkan sampah yang masih dapat digunakan, 4) Kurangnya pengetahuan masyarakat tentang pemberantasan sarang nyamuk dan bahaya BABs.

Peran serta masyarakat dalam pengelolaan lingkungan merupakan kesediaan masyarakat untuk membantu berhasilnya program pengembangan pengelolaan lingkungan sesuai dengan kemampuan setiap orang tanpa mengorbankan kepentingan diri sendiri. Tanpa adanya peran serta masyarakat semua program pengelolaan persampahan yang direncanakan akan sia-sia. Salah satu pendekatan masyarakat untuk dapat membantu program pemerintah dalam keberhasilan adalah membiasakan masyarakat pada tingkah laku yang sesuai dengan program persampahan yaitu merubah persepsi masyarakat terhadap pengelolaan sampah yang tertib, lancar dan merata, merubah kebiasaan masyarakat dalam pengelolaan sampah yang kurang baik dan faktor-faktor sosial, struktur dan budaya setempat (Wibowo dan Djajawinata, 2004). Menurut Syafrudin (2004), salah satu alternatif yang bisa dilakukan adalah melaksanakan program pengelolaan sampah berbasis masyarakat, seperti minimalisasi limbah dan melaksanakan 5 R (Reuse, Recycling, Recovery, Replacing dan Refilling).

Berdasarkan permasalahan tersebut, maka ditetapkan tujuan program KKN ini adalah memberdayakan masyarakat Baran dalam kepedulian lingkungan.

\section{B. METODE PELAKSANAAN}

Untuk mencapai tujuan yang diharapkan, program KKN di Kelurahan Baran dilakukan dengan pemberdayaan masyarakat melalui pendidikan masyarakat, difusi ilmu pengetahuan dan teknologi dan praktek langsung. Ringkasan metode pelaksanaan beserta jam kerja efektif mahasiswa (JKEM) tersaji pada table I. 
Diterbitkan oleh Lembaga Pengabdian kepada Masyarakat

Universitas Ahmad Dahlan Yogyakarta

Tabel I. Metode, Kegiatan, JKEM dan keterlibatan mahasiswa

\begin{tabular}{|l|l|l|l|l|}
\hline No & Metode & Kegiatan & JKEM & $\begin{array}{l}\text { Jumlah } \\
\text { mahasiswa } \\
\text { yang terlibat }\end{array}$ \\
\hline 1 & $\begin{array}{l}\text { Pendidikan } \\
\text { masyarakat }\end{array}$ & $\begin{array}{l}\text { Menyelenggarakan } \\
\text { penyuluhan dan praktek } \\
\text { PHBS tentang cuci tangan }\end{array}$ & 5 x 2 jam & 12 \\
\cline { 3 - 5 } & $\begin{array}{l}\text { Menyelenggarakan } \\
\text { penyuluhan dan praktek } \\
\text { PHBS tentang sikat gigi }\end{array}$ & 5 x 2jam & 15 \\
\hline 2 & \multirow{2}{*}{ Difusi iptek } & $\begin{array}{l}\text { Menyelenggarakan pelatihan } \\
\text { pembuatan Lilin } \\
\text { Aromaterapi }\end{array}$ & $1 \times 2$ jam & 27 \\
\hline 3 & Praktek & $\begin{array}{l}\text { Pelatihan pembuatan Sabun } \\
\text { Cair }\end{array}$ & $1 \times 2$ jam & 12 \\
\cline { 3 - 5 } & $\begin{array}{l}\text { Penyuluhan bahaya BABs } \\
\text { Melakukan praktek }\end{array}$ & 2 x 2 jam \\
penanaman toga & 27 & 27 \\
\hline
\end{tabular}

\section{HASIL, PEMBAHASAN DAN DAMPAK}

1) Profil Desa

Kelurahan Baran berada di Kecamatan Ambarawa, Kabupaten Semarang, Jawa Tengah. Wilayah kelurahan Baran dapat dijangkau dari Kantor Kecamatan Ambarawa kurang lebih 5 menit dengan jarak kurang lebih 1,5 km.

Kelurahan Baran memiliki batasan - batasan wilayah sebagai berikut:

Batas Sebelah Utara : Desa Milir

Batas Sebelah Selatan : Desa Pasekan

Batas Sebelah Barat : Desa Jetis

Batas Sebelah Timur : Kelurahan Kranggan

Adapun peta dari Kelurahan Baran tersaji pada gambar 1

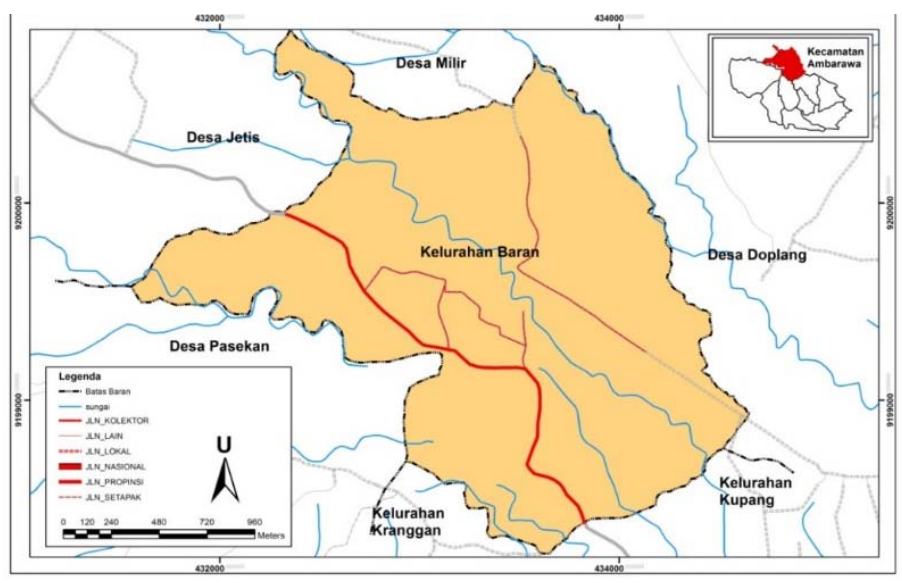

Gambar 1. Kelurahan Baran

Sumber: Bappeda Kabupaten Semarang, 2011 
Jumlah penduduk dikelurahan baran yaitu 6157 dengan pengelompokan penduduk berdasarkan usia dan jenis kelamin tersaji pada table II, gambar 2 dan gambar 3.

Tabel II. Penduduk Baran Berdasarkan Usia

\begin{tabular}{|l|c|c|}
\hline \multicolumn{1}{|c|}{ Usia } & Laki-laki & Perempuan \\
\hline $0-4$ & 174 & 186 \\
\hline $5-9$ & 234 & 172 \\
\hline $10-14$ & 242 & 183 \\
\hline $15-19$ & 275 & 218 \\
\hline $20-24$ & 235 & 243 \\
\hline $25-29$ & 237 & 255 \\
\hline $30-34$ & 297 & 321 \\
\hline $35-39$ & 286 & 287 \\
\hline $40-44$ & 264 & 258 \\
\hline $45-49$ & 208 & 235 \\
\hline $50-54$ & 175 & 192 \\
\hline $55-59$ & 178 & 152 \\
\hline $60-64$ & 107 & 113 \\
\hline $65-69$ & 50 & 62 \\
\hline $70-74$ & 64 & 57 \\
\hline$>75$ & 101 & 96 \\
\hline Jumlah & 3127 & $\mathbf{3 0 3 0}$ \\
\hline
\end{tabular}

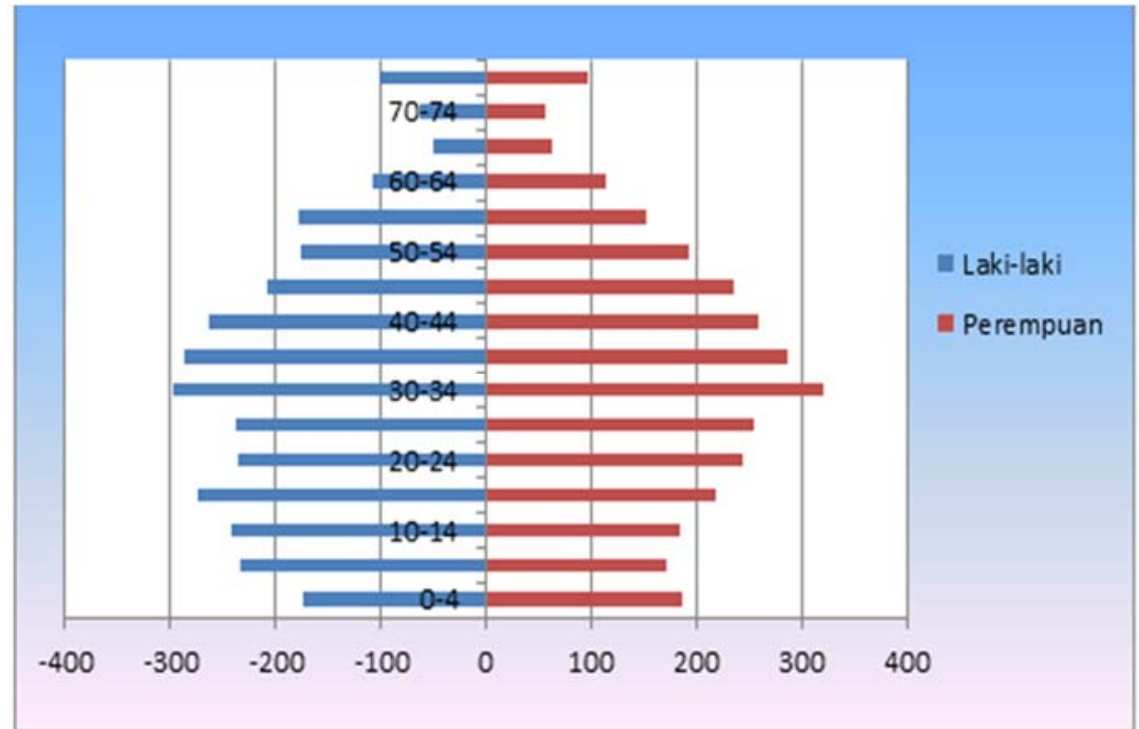

Gambar 2. Piramida Penduduk Kelurahan Baran

Sebagaimana tertera di atas, menunjukkan bahwa penduduk di Kelurahan Baran pada kelompok usia produktif (usia 15-49 tahun) lebih banyak daripada penduduk pada kelompok usia non produktif. 


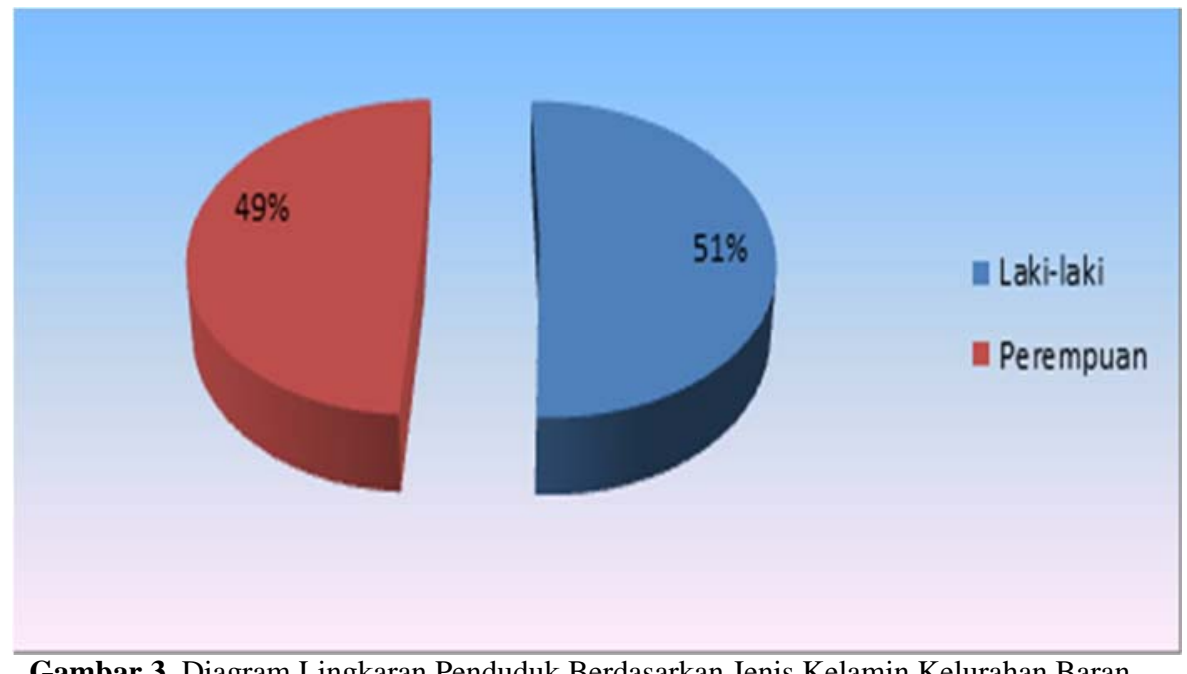

Gambar 3. Diagram Lingkaran Penduduk Berdasarkan Jenis Kelamin Kelurahan Baran

Mayoritas penduduk Kelurahan Baran adalah menganut agama Islam sebanyak 5944, dengan jumlah penganut laki-laki sebanyak 3049 dan penganut perempuan sebanyak 2895. Untuk agama katholik sebanyak 73, dengan jumlah penganut laki-laki sebanyak 40 dan penganut perempuan sebanyak 33. Agama Kristen sebanyak 128, dengan jumlah penganut laki-laki sebanyak 68 dan penganut perempuan sebanyak 60. Dan penduduk yang menganut kepercayaan sebanyak 12, dengan jumlah penganut laki-laki sebanyak 7 dan penganut perempuan sebanyak 5. Untuk Hindu, Budha, dan Konghucu tidak ada yang menganut.

2) Gambaran Pelaksanaan

Gambar aktivitas mahasiswa KKN UAD dan masyarakat Kelurahan Baran dalam program PHBS tersaji pada gambar 4.

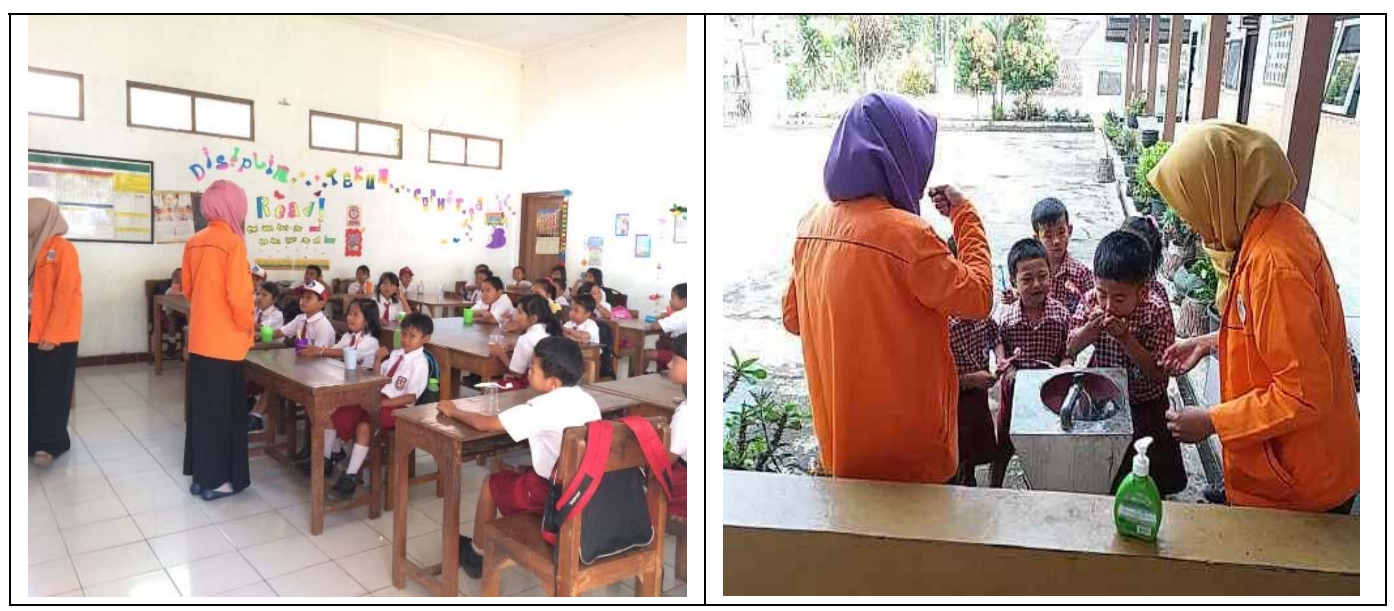




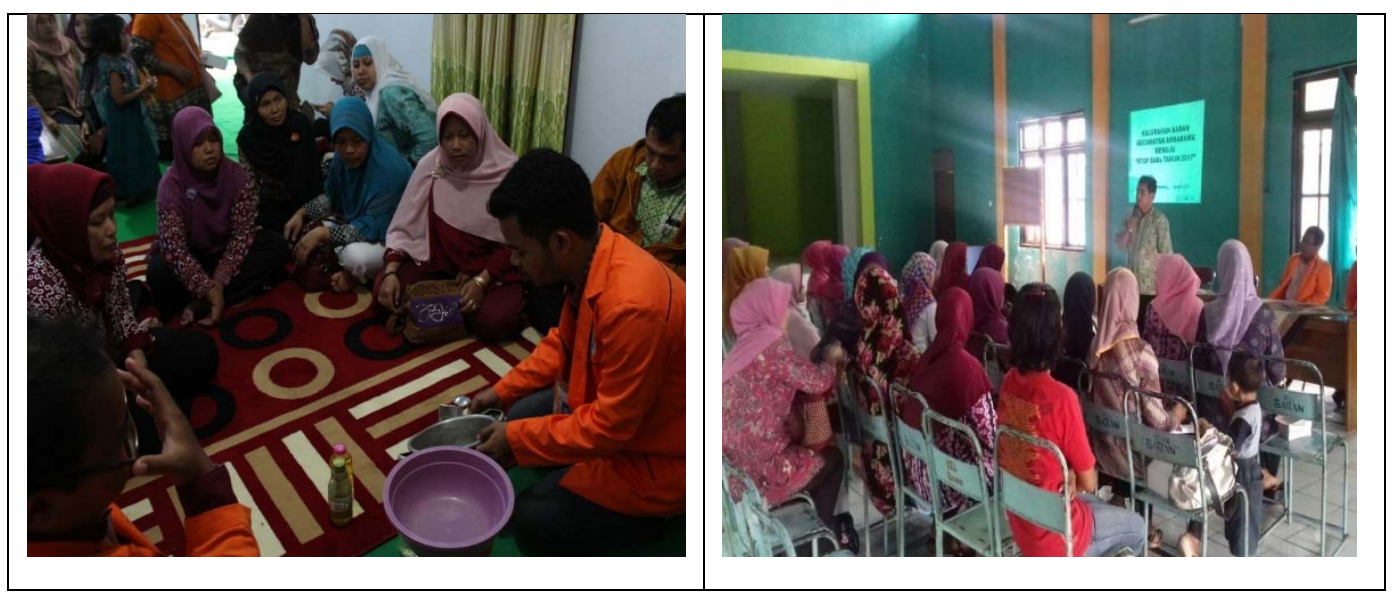

Gambar 4. Aktivitas mahasiswa KKN UAD dan masyarakat Kelurahan Baran dalam program PHBS

Dari gambar 4 terlihat program KKN di Kelurahan Baran dapat terlaksana dengan partisipasi masyarakat yang cukup tinggi dengan kata lain dapat memperdayakan masyarakat dalam program-program yang telah direncanakan. Dampak dari kegiatan KKN ini adalah: 1) tercipta kesadaran masyarakat sasaran tentang pentingnya PHBS, 2) peningkatan pengetahuan masyarakat dalam mengolah sampah, 3) masyarakat terampil membuat karya kreatif plasti bekas, 4) peningkatan pengetahuan masyarakat tentang Demam Berdarah dan bahaya BABs

\section{KESIMPULAN}

Program KKN UAD dalam memberdayakan masyarakat Kelurahan terhadap kepedulian dan Kebersihan lingkungan telah berjalan dengan baik.

\section{DAFTAR PUSTAKA}

Syafrudin, 2004, Pengelolaan Sampah Berbasis Masyarakat. Prosiding, Diskusi Interaktif Pengelolaan Sampah Terpadu, Program Magister Ilmu LingkunganUniversitas Diponegoro, Semarang.

Ni Komang Ayu Artiningsih, 2008, Peran Serta Masyarakat Dalam Pengelolaan

Sampah Rumah Tangga, Disertasi, Program Magister Ilmu Lingkungan Program Pasca Sarjana Universitas Diponegoro Semarang.

Wibowo A dan Djajawinata D.T, 2004. Penanganan Sampah Perkotaan Terpadu. Diakses tanggal 4 Desember 2016 pada halaman

www.kkpi.go.id 